\title{
Polycystic Ovary Syndrome, Affective Symptoms, and Neuroactive Steroids: a Focus on Allopregnanolone
}

\author{
Lindsay R. Standeven ${ }^{1}$ • Elizabeth Olson ${ }^{2}$ - Nicole Leistikow ${ }^{3}$ • Jennifer L. Payne ${ }^{1,4}$ • Lauren M. Osborne ${ }^{1,4}$. \\ Liisa Hantsoo ${ }^{1}$
}

Accepted: 24 March 2021 / Published online: 21 April 2021

(C) The Author(s) 2021

\begin{abstract}
Purpose of Review To provide an overview of existing studies on alterations in gonadal and neuroactive steroids (NASs) and mood symptoms among women with polycystic ovary syndrome (PCOS).

Recent Findings Recent studies have demonstrated a previously underappreciated association between PCOS and comorbid depression and anxiety. However, most studies on affective symptoms among women with PCOS have been cross-sectional, limiting our knowledge about fluctuations in symptoms over the menstrual cycle and reproductive lifespan for women with PCOS, as well as the potential interplay between NAS alterations and mood symptoms. Changes in the NAS allopregnanolone (ALLO) have been implicated in several reproductive-related psychiatric disorders (e.g., premenstrual dysphoric disorder (PMDD) and postpartum depression (PPD)) as well as in normal reproductive functioning, warranting further investigation for its potential role in the psychiatric symptoms observed in women with PCOS.

Summary Prospective studies evaluating associations between psychiatric symptoms and NAS are needed to elucidate the biological causes of the increased rates of psychiatric symptoms among women with PCOS and inform clinical treatment. ALLO, with its role in normal reproductive function, menstrual dysregulation among women with PCOS, and reproductiverelated psychiatric conditions, makes it a particularly intriguing candidate for future investigation.
\end{abstract}

Keywords Polycystic ovary syndrome $\cdot$ Neurosteroids $\cdot$ Mood $\cdot$ Anxiety $\cdot$ Depression

This article is part of the Topical collection on Reproductive Psychiatry and Women's Health

Lindsay R. Standeven

Lrothen2@jhmi.edu

1 Women's Mood Disorders Center, Department of Psychiatry and Behavioral Sciences, Johns Hopkins University School of Medicine, Baltimore, MD, USA

2 School of Medicine, University of Maryland, Baltimore, MD, USA

3 Department of Psychiatry, University of Maryland, Baltimore, MD, USA

4 Department of Gynecology and Obstetrics, Johns Hopkins University School of Medicine, Baltimore, MD, USA

\section{Associations Between Polycystic Ovary Syndrome and Symptoms of Depression and Anxiety}

Polycystic ovary syndrome (PCOS) is both common and costly. It is the most widespread endocrine disorder of reproductiveaged women globally and has a prevalence ranging from 4 to $21 \%$, depending upon the criteria used for diagnosis and the population studied [1-6]. Costs for medical visits related to PCOS in the USA are estimated at $\$ 1.16$ billion annually [7]. A syndrome of heterogenous manifestations and severity, PCOS is typically diagnosed based on exclusion of other causes and the presence of several clinical characteristics: the eponymous cystic ovaries, irregular menstrual cycles or anovulation, and hyperandrogenism with its multiple manifestations [2, 3, 8]. Sequelae include infertility and obstetrical complications; symptoms of hyperandrogenism including hirsutism, acne, and alopecia; and cardiometabolic risks including dyslipidemia, impaired glucose tolerance, insulin resistance, diabetes, and hypertension 
$[2,8]$. Treatment has historically focused on improving reproductive function and managing symptoms such as weight gain, insulin resistance, hirsutism, and acne [3].

Less well studied is PCOS's link to comorbid depression and anxiety symptoms. A meta-analysis of more than 3000 subjects found that twice as many women with PCOS had depressive symptoms compared to women without PCOS ( $36 \%$ vs. $14 \%$ ), and that over four times as many women with PCOS had anxiety symptoms (42\% vs. 9\%) [9]. This association only strengthened when severity of symptoms was considered. The same study found that women with PCOS had moderate to severe depressive symptoms at an odds ratio of 4.18 compared to women without PCOS and moderate to severe anxiety symptoms at an odds ratio of 6.55 . When restricted to clinical depressive or anxiety disorders, women with PCOS continue to be diagnosed at increased rates [10-13]. Alarmingly, one small study found that women with PCOS attempted suicide at 7 times the rate of women without PCOS [14].

Historically, increased rates of depression and anxiety symptoms in women with PCOS were thought to be sufficiently explained by struggles to have children, obesity, and signs of hyperandrogenism causing low self-esteem or other psychological stress [15-17]. These conclusions are more anchored in stereotypical social constructs of women than in a rigorous analysis using matched comparator groups [18]. When controls have been matched for factors such as BMI, family history of depression, and infertility, numerous studies have found higher rates of depression and depression symptoms in women with PCOS, a discovery that has begun to propel the search for a biochemical etiology of this association $[9,12,15,18,19]$.

One potential nexus linking PCOS with depression and anxiety symptoms is the gonadal and neuroactive steroids (NASs), derivatives of cholesterol that have potent actions in the brain and have been implicated in all three phenomena [20]. NAS can be synthesized in the brain (where they are called neurosteroids) and in the adrenal glands or gonads, and they all derive from traditional gonadal steroids: progesterone, deoxycorticosterone, and testosterone. They are broadly classified into three groups based on their biochemical structure: (1) pregnane neurosteroids (e.g., allopregnanolone (ALLO) and allotetrahydrodeoxycorticosterone (THDOC)), (2) sulfated neurosteroids (e.g., dehydroepiandrosterone sulfate (DHEAS) and pregnenolone sulfate (PREGS)), and (3) androstane neurosteroids (e.g., androstanediol and androstanol) (see Table 1). NASs cross the blood-brain barrier and, in addition to modifying serotonergic and glutamatergic tone, modify the inhibitory $\gamma$-aminobutyric acid (GABA) system [21-23]. Different NASs can be more or less inhibitory, depending on the extent of their allosteric or direct activation and potentiation of the GABA-A receptor [24]. Psychotropic drugs can modulate NAS levels, and NAS plasma concentrations appear to change in patients with depressive syndromes [25] (for a complete review of NAS in psychiatric illness, see [25] and [26]).

Changes in NAS levels have been implicated in mood and anxiety symptoms at menarche, pre-menstrually, in the postpartum, and during perimenopause [24, 27-34]. NAS may also play a role in PCOS; modulation of NAS has been linked to successful treatment of some aspects of PCOS [35]. There are recent data suggesting that women with PCOS show improvement in depressive and anxiety symptoms with oral contraceptive pills (OCPs), as do some women with PMDD [36]. This supports the idea that changes in NAS across women's reproductive cycles may underlie the observed psychiatric symptoms. However, it is not known if women with PCOS experience premenstrual exacerbations of mood symptoms, nor what percentage may have comorbid PMDD.

Most studies on affective symptoms among women with PCOS have been cross-sectional, limiting our knowledge about fluctuations in symptoms over the menstrual cycle or reproductive lifespan. To our knowledge, there has been only one prospective study following women with PCOS for the

Table 1 Selected endogenous neurosteroids by category and action at GABA-A receptor

\begin{tabular}{llll}
\hline Classification & Neurosteroids & Nomenclature & Effect at GABA-A receptor \\
\hline Pregnane & & & Potentiates \\
& Allopregnanolone (ALLO) & $5 \alpha$-pregnane-3 $\alpha$-ol-20-one & Potentiates \\
Allotetrahydrodeoxycorticosterone (THDOC) & $5 \alpha$-pregnane-3 $\alpha, 21$-diol-20-one & Potentiates \\
& & & Potentiates \\
Sulfated & Androstanediol & $5 \alpha$-androstan-3 $\alpha, 17 \beta$-diol & Inhibits \\
& Androstanol & $3 \alpha, 5 \alpha$-androstenol & Inhibits \\
\hline
\end{tabular}

Nomenclature obtained and table adopted from Reddy et al. (2010) [21] 
onset of depression and anxiety disorders, and it did not attempt to track menstrual patterns [13], thus limiting any conclusions about whether women with PCOS may also suffer from premenstrual exacerbation of affective symptoms. Furthermore, there are no known prospective studies following both hormonal fluctuations and symptoms of depression and anxiety across PCOS menstrual cycles (see Table 2). Tracing the symptoms of PCOS, depression, and anxiety across time in relation to fluctuations of gonadal steroids and NAS is necessary to explore the etiologies of their association. The remainder of this paper reviews what is known about the role of gonadal steroids and NAS in PCOS and mood and anxiety symptoms to identify targets for future research.

\section{Gonadal and Neuroactive Steroids Implicated in Depression, Anxiety, and PCOS}

Many studies demonstrate alterations in gonadal steroids (namely testosterone and progesterone) and NAS in women with PCOS [77-80]. Given that hyperandrogenism is a pathognomonic feature of PCOS, the majority of studies have focused on the role of altered androgens and their products (e.g., testosterone, DHEA and DHEA-S, androstenedione, and androstenediol). Average levels of testosterone and androstenedione can be higher in women with PCOS as compared to healthy controls $[80,81]$. Similarly, many PCOS patients have higher DHEA-S levels [40]. These combined pathological biochemical findings have elicited curiosity about whether alterations in select gonadal steroids and NAS may underlie the greater risk for depression and anxiety symptoms observed in women with PCOS. We will therefore provide an overview of the existing studies on alterations in gonadal and NAS and mood symptoms among women with PCOS (below and in Table 1).

\section{Testosterone}

Since alterations in testosterone levels are common in PCOS, most studies have focused on the association between aberrations in testosterone levels and mood symptoms. To date, there is conflicting evidence on the association between depressive symptoms and testosterone levels. In Jedel et al.'s (2011) study of 72 women with PCOS, circulating concentrations of testosterone were lower in women with PCOS with symptoms of depression as compared to women with PCOS without symptoms of depression [63]. Yet, another study found a positive correlation between elevated testosterone and depressive symptoms [82]. A study by Weiner and colleagues demonstrated a curvilinear relationship between testosterone levels and depression in women with and without PCOS; i.e., the most severe depression was associated with levels below and above the normal range [76]. A 2013 study by Annagür et al. did not observe differences in testosterone levels between depressed PCOS and non-depressed PCOS women [40]. Other studies found no association between testosterone and depression in women with PCOS [39, 45, 83], and some even show an inverse correlation between free testosterone and depressive symptoms [61, 84]. The evidence on testosterone levels and depressive symptoms in women with PCOS remains inconclusive, necessitating further research on alternative NASs that may play a role.

\section{DHEA-S}

Evidence implicating DHEA-S (the sulfated form of DHEA and an excitatory NAS) in the increased risk of depression in PCOS women is also mixed. Comparing PCOS patients with major depressive disorder (MDD) to PCOS patients without MDD or other psychiatric illness, Annagür and colleagues found that DHEA-S levels were significantly higher in the depressed PCOS group [40]. On the other hand, in a review by Dokras et al. and study by Hollinrake et al., there were no significant differences in adrenal androgen DHEA-S levels between depressed women with PCOS and non-depressed women with PCOS $[12,16]$. Amiri and colleagues found no significant relationship between DHEA-S levels and psychosocial-emotional status or quality of life, except for depressed sexual function [39]. No other human studies to date have directly compared DHEA-S levels in depressed versus healthy PCOS women.

\section{Androstenediol}

Levels of androstenediol, a reduced metabolite of testosterone and androstenedione, are known to be elevated in women with PCOS [79]. Similarly, elevated levels of androstenedione have been observed [78, 79]. Jedel et al. (2011) reported diminished levels of androstenediol among women with PCOS and depression [61]. No other papers have been published on the relationship between androstenediol levels in PCOS women and mood symptoms.

\section{Progesterone and 17-0H Progesterone}

Comparing PCOS patients with MDD to PCOS patients without any diagnosed disorder, 17-OH progesterone, a metabolite of progesterone, was significantly higher in the depressed PCOS group [61]. A more recent study by Klimczak and colleagues similarly reported that depressed patients with PCOS had greater progesterone levels than non-depressed PCOS patients [63]. No other human studies have directly compared these levels in depressed versus healthy PCOS women. Two studies have demonstrated generally elevated levels of 17-OH progesterone in PCOS women, but analysis 


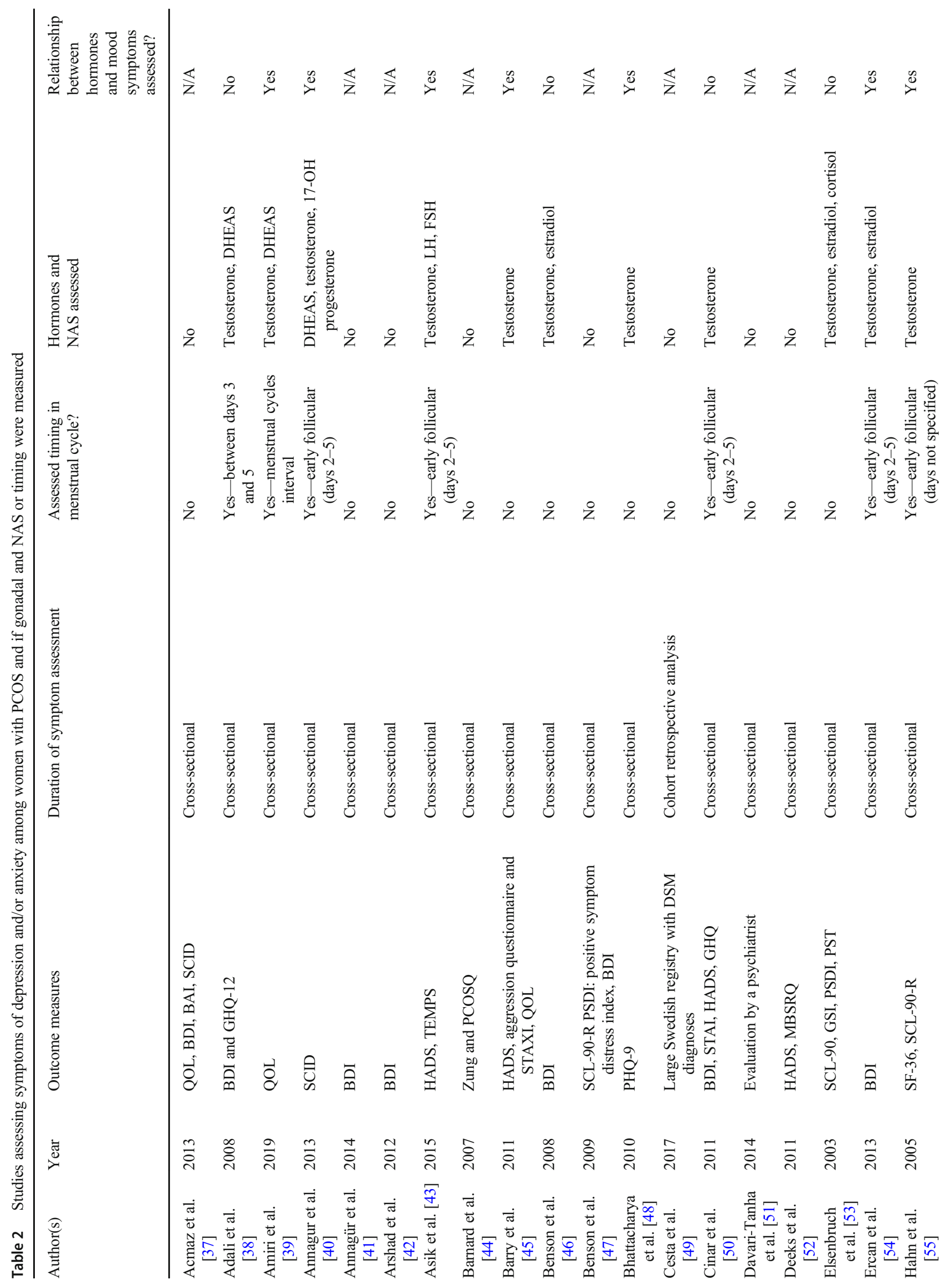




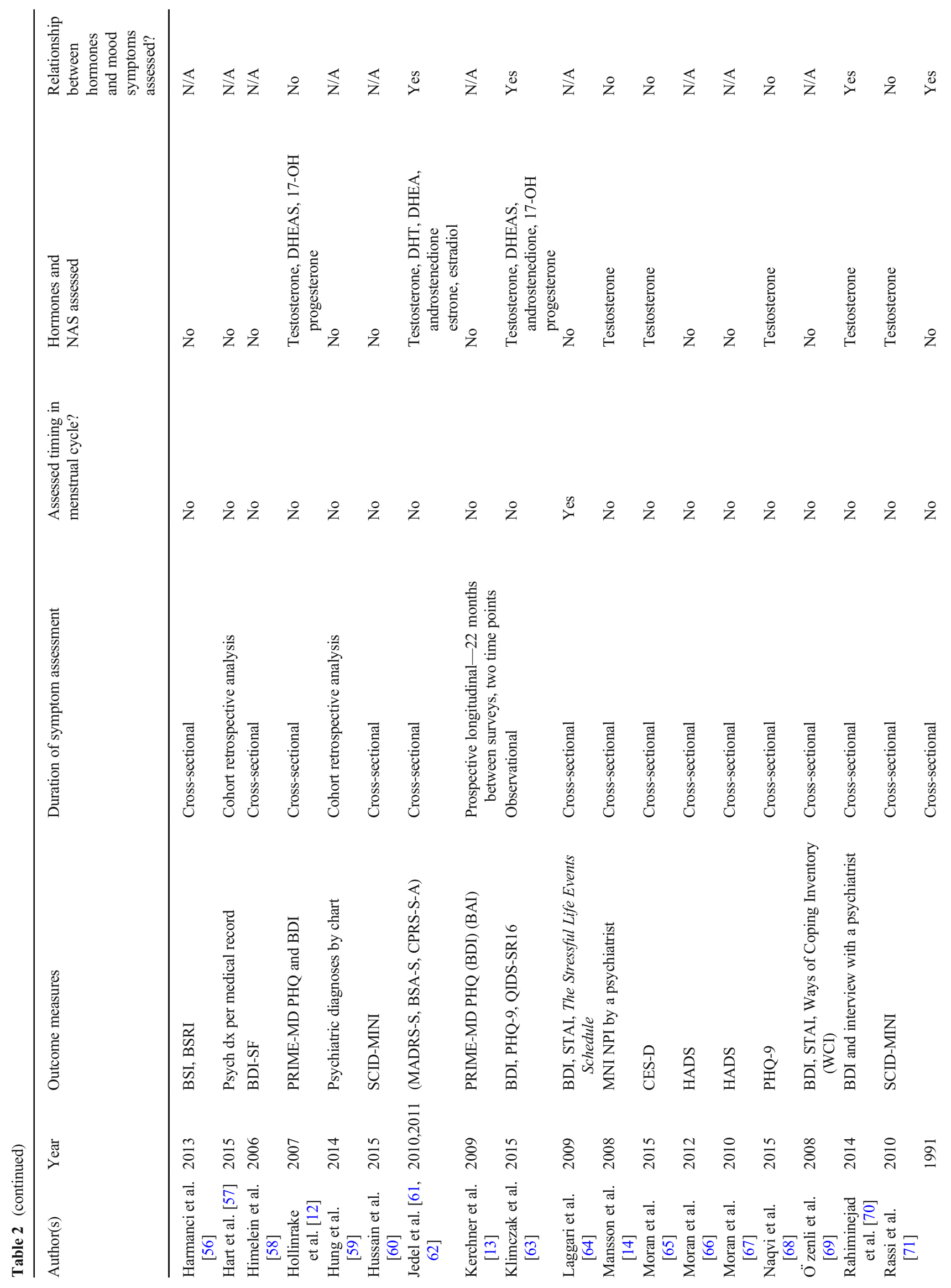




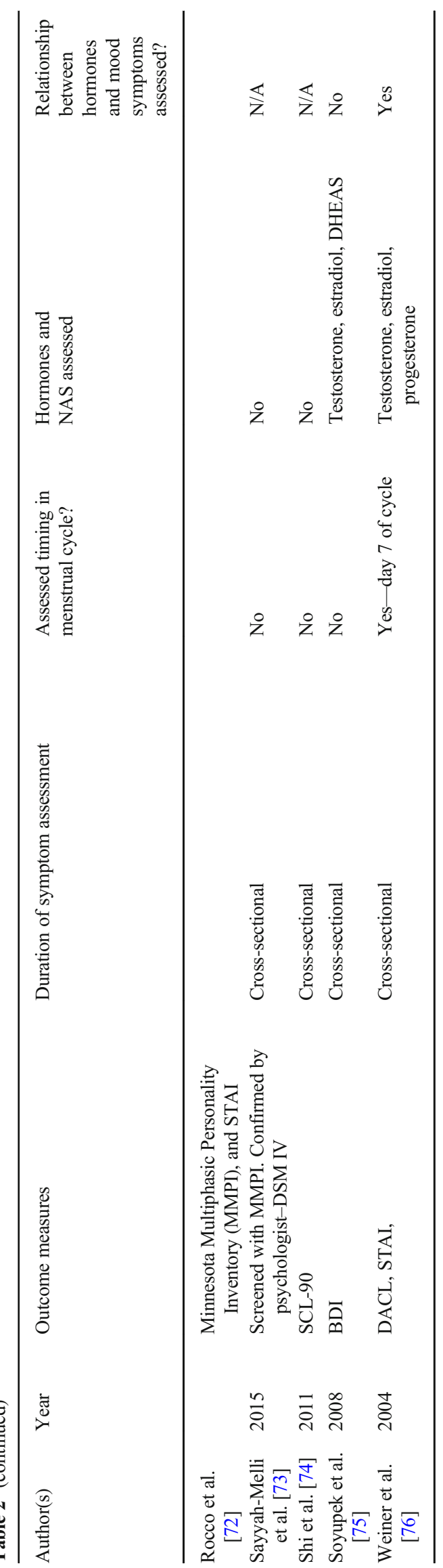

was not specific to women diagnosed with mood disorders $[79,80]$.

\section{Allopregnanolone}

ALLO, the $3 \alpha, 5 \alpha$-reduced metabolite of progesterone, is produced and released from the adrenal glands and ovaries following adrenocorticotropic hormone (ACTH) and gonadotropin-releasing hormone $(\mathrm{GnRH})$ stimulation [85]. ALLO levels fluctuate over the reproductive lifespan: with plasma levels changing across the menstrual cycle (highest during the early luteal phase), across pregnancy (highest in the third trimester), and during the menopausal transition (fluctuating, but declining with time). ALLO is also a potent allosteric modulator of the GABA-A receptor that has significant anxiolytic effects [24, 86, 87]. Given its dual role in both reproductive functioning and the neuromodulation of stress and anxiety, it is not surprising that alterations in ALLO have been implicated in psychiatric illness at times of reproductive transition, namely postpartum depression (PPD) [41-51], PMDD [37-40, 88-94], and perimenopausal depression [52-58].

Evidence over the past decade suggests that ALLO plays a critical role in normal menstrual cycling [35, 79, 81, 95], and alterations in ALLO may contribute to the reproductive pathology observed in women with PCOS [88, 96-98]. Given that women with PCOS do not demonstrate typical menstrual cycling, it is possible that alterations in ALLO levels may be related to their ovarian dysfunction. Animal models support the notion that elevated ALLO may underlie the pathology observed in PCOS. Following intracerebrovascular injection of ALLO into rats, Guiliani et al. (2011) found an increase in LH release [89]; changes in ovarian steroid production and ovarian morphology; decreased follicular development; and reduced ovulation - the same phenotypic profile observed in women with PCOS $[90,91]$.

Evidence from clinical research studying ALLO levels among women with PCOS has been mixed, with some studies supporting elevated levels of ALLO among women with PCOS [35, 78], another showing low ALLO levels [88], and one showing no differences in ALLO levels between PCOS women and controls [81]. Treatment trials of metformin (an oral anti-hyperglycemic found to reduce androgen levels, improve insulin resistance, and restore menstrual frequency and fertility in many women with PCOS) also support alterations in ALLO levels as well as a dysregulation of the normal signaling pattern among GnRH, LH, ACTH, and ALLO, though not always in the same direction. Genazzani et al. (2010) found lower ALLO levels in PCOS women compared to healthy controls prior to treatment with metformin, and speculated that these lower levels may be responsible for observed elevations in psychiatric symptoms [88, 92]. Ganzzanie et al. (2006), on the other hand, found that following 6 months of 
treatment with metformin participants demonstrated significant decreases in androgen, LH, and ALLO levels and restored LH and ALLO coupled release [35]. In one of the only known intervention studies for mood, Hahn et al. (2006) found a significant improvement in quality of life, depression, anxiety, and aggression measures following 6 months of metformin treatment [93], though changes in NAS (including ALLO) were not assessed.

In addition to alterations in absolute ALLO levels, altered sensitivity at ALLO receptor targets (GABA-A) may contribute to the etiology of PCOS [78]. Among 9 women with PCOS, ALLO levels were elevated compared to overweight non-PCOS and normal weight non-PCOS controls. Interestingly, the PCOS women also had lower sedation scores (measured by saccadic eye velocity) following intravenous injection of ALLO, indicating reduced GABA-A receptor sensitivity. This finding suggests that the observed elevations in total ALLO among women with PCOS may be a compensatory response to reduced receptor sensitivity rather than the cause of dysregulation. No studies to our knowledge, however, have measured a relationship among alterations in GABA-A receptor sensitivity, ALLO levels, and psychiatric symptoms among women with PCOS.

\section{Discussion}

For too long, PCOS has been viewed as an endocrine disorder without adequate attention to the interface between observed hormonal alterations and psychiatric symptoms. Though research over the past decade has been critical in confirming the increased psychiatric burden experienced by women with PCOS, additional studies are needed to characterize adequately the course of psychiatric symptoms and their relationship to biology. Indeed, many questions remain. Do women with PCOS experience premenstrual exacerbation of psychiatric symptoms? Or, conversely, do they have persistently elevated symptoms due to a lack of menstrual cycling and hormonal fluctuations? Does the severity or type of psychiatric symptoms differ across the different PCOS phenotypes (e.g., those with hyperandrogenism versus not)?

At present, studies investigating the biological causes of the psychiatric symptoms among women with PCOS are limited. Most studies have measured NAS cross-sectionally, in order to diagnose and classify PCOS subtypes, rather than for the purpose of assessing associations with psychiatric symptoms. Of the studies that have assessed NAS and mood symptoms, most have also done so only cross-sectionally (limiting longer term conclusions), focused solely on depressive symptoms (limiting our appreciation of other symptoms and diagnoses), and focused on androgens, an approach that does not apply across all PCOS phenotypes. Larger prospective studies measuring associations among psychiatric diagnoses, psychiatric symptoms, and all three classes of NAS are needed to guide future research.

To our knowledge, there are no studies prospectively and concurrently measuring both ALLO levels and psychiatric symptoms among women with PCOS. Given recent research revealing ALLO's role in 3 important phenomena-normal reproductive functioning, menstrual dysregulation among women with PCOS, and psychiatric symptoms among women with PMDD, PPD, and perimenopausal depression-ALLO is an ideal candidate linking both the psychiatric symptoms and menstrual dysregulation observed in women with PCOS. Will we find that total ALLO levels or ALLO target dysregulation (e.g., changes in receptor plasticity, gene expression, or receptor sensitivity) underlie symptoms of depression or anxiety in women with PCOS? Are the symptoms caused by a paradoxical sensitivity to ALLO (as previously suggested among women with PMDD), reduced GABA-A receptor sensitivity (perhaps due to persistently elevated ALLO), an inability to upregulate or modulate GABA-A receptor subunits (as may be the case in PPD), or reduced total ALLO levels (due to lack of ovarian production during anovulatory cycles)? Will alterations in ALLO be entirely unrelated to the psychiatric symptoms manifested?

Improved understanding of the biological etiology of psychiatric symptoms for PCOS women is also critical in helping to determine adequate treatment approaches. For example, while OCPs remain the treatment of choice to regulate the menstrual cycle for women with PCOS, few studies have assessed their effect on psychiatric symptomatology in this population. Similarly, while metformin is used to enhance insulin sensitivity, it remains unknown if metformin, through modification of NAS levels, may improve psychiatric symptoms. If so, should it be prescribed as part of standard psychiatric practice for women with PCOS? Lastly, there are no studies to date assessing differences in psychotropic responsivity among women with PCOS. Are lower SSRI doses needed for symptom remission (as is the case for many women with PMDD) [94], or do women with PCOS respond similarly to patients with MDD or generalized anxiety disorder?

Answering these questions is critical to raising awareness of the psychiatric needs of this vulnerable population and advocating for improved screening and treatment of psychiatric symptoms by colleagues in internal medicine, family medicine, endocrinology, and gynecology, who often provide frontline care to women with PCOS. Without increased screening and education about high rates of psychiatric comorbidity, many women with PCOS may be left untreated. A first step to providing comprehensive care will be longitudinal research studies examining the links among PCOS, depression, anxiety, and neuroactive steroids. Only once we understand this intricate relationship will PCOS be viewed and treated as the complex endocrinological and psychiatric syndrome it is. 
Open Access This article is licensed under a Creative Commons Attribution 4.0 International License, which permits use, sharing, adaptation, distribution and reproduction in any medium or format, as long as you give appropriate credit to the original author(s) and the source, provide a link to the Creative Commons licence, and indicate if changes were made. The images or other third party material in this article are included in the article's Creative Commons licence, unless indicated otherwise in a credit line to the material. If material is not included in the article's Creative Commons licence and your intended use is not permitted by statutory regulation or exceeds the permitted use, you will need to obtain permission directly from the copyright holder. To view a copy of this licence, visit http://creativecommons.org/licenses/by/4.0/.

\section{References}

1. Azziz R, Woods KS, Reyna R, Key TJ, Knochenhauer ES, Yildiz $\mathrm{BO}$. The prevalence and features of the polycystic ovary syndrome in an unselected population. J Clin Endocrinol Metab. 2004;89(6): 2745-9.

2. Escobar-Morreale HF. Polycystic ovary syndrome: definition, aetiology, diagnosis and treatment. Nat Rev Endocrinol. 2018 May;14(5):270-84.

3. Goodman NF, Cobin RH, Futterweit W, Glueck JS, Legro RS, Carmina E, et al. American Association of Clinical Endocrinologists, American College of Endocrinology, and Androgen Excess and PCOS Society disease state clinical review: guide to the best practices in the evaluation and treatment of polycystic ovary syndrome-part 1. Endocr Pract Off J Am Coll Endocrinol Am Assoc Clin Endocrinol. 2015;21(11):1291-300.

4. Lizneva D, Suturina L, Walker W, Brakta S, Gavrilova-Jordan L, Azziz R. Criteria, prevalence, and phenotypes of polycystic ovary syndrome. Fertil Steril. 2016;106(1):6-15.

5. Wolf WM, Wattick RA, Kinkade ON, Olfert MD. Geographical prevalence of polycystic ovary syndrome as determined by region and race/ethnicity. Int J Environ Res Public Health [Internet]. 2018 Nov [cited 2020 Jun 21];15(11). Available from: https://www.ncbi. nlm.nih.gov/pmc/articles/PMC6266413/

6. Yildiz BO, Bozdag G, Yapici Z, Esinler I, Yarali H. Prevalence, phenotype and cardiometabolic risk of polycystic ovary syndrome under different diagnostic criteria. Hum Reprod. 2012;27(10): 3067-73.

7. Jason J. Polycystic ovary syndrome in the United States: clinical visit rates, characteristics, and associated health care costs. Arch Intern Med. 2011;171(13):1209-11.

8. Azziz R, Carmina E, Dewailly D, Diamanti-Kandarakis E, EscobarMorreale HF, Futterweit W, et al. The Androgen Excess and PCOS Society criteria for the polycystic ovary syndrome: the complete task force report. Fertil Steril. 2009;91(2):456-88.

9. Cooney LG, Lee I, Sammel MD, Dokras A. High prevalence of moderate and severe depressive and anxiety symptoms in polycystic ovary syndrome: a systematic review and meta-analysis. Hum Reprod Oxf Engl. 2017;32(5):1075-91.

10. Brutocao C, Zaiem F, Alsawas M, Morrow AS, Murad MH, Javed A. Psychiatric disorders in women with polycystic ovary syndrome: a systematic review and meta-analysis. Endocrine. 2018;62(2): 318-25.

11. Cesta CE, Månsson $\mathrm{M}$, Palm C, Lichtenstein P, Iliadou AN, Landén M. Polycystic ovary syndrome and psychiatric disorders: comorbidity and heritability in a nationwide Swedish cohort. Psychoneuroendocrinology. 2016;73:196-203.

12. Hollinrake E, Abreu A, Maifeld M, Van Voorhis BJ, Dokras A. Increased risk of depressive disorders in women with polycystic ovary syndrome. Fertil Steril. 2007;87(6):1369-76.
13. Kerchner A, Lester W, Stuart SP, Dokras A. Risk of depression and other mental health disorders in women with polycystic ovary syndrome: a longitudinal study. Fertil Steril. 2009;91(1):207-12.

14. Månsson M, Holte J, Landin-Wilhelmsen K, Dahlgren E, Johansson A, Landén M. Women with polycystic ovary syndrome are often depressed or anxious-a case control study. Psychoneuroendocrinology. 2008;33(8):1132-8.

15. Damone AL, Joham AE, Loxton D, Earnest A, Teede HJ, Moran LJ. Depression, anxiety and perceived stress in women with and without PCOS: a community-based study. Psychol Med. 2019;49(09):1510-20.

16. Dokras A, Clifton S, Futterweit W, Wild R. Increased prevalence of anxiety symptoms in women with polycystic ovary syndrome: systematic review and meta-analysis. Fertil Steril. 2012;97(1):225230.e2.

17. Podfigurna-Stopa A, Luisi S, Regini C, Katulski K, Centini G, Meczekalski B, et al. Mood disorders and quality of life in polycystic ovary syndrome. Gynecol Endocrinol. 2015;31(6):431-4.

18. Farrell K, Antoni M. Insulin resistance, obesity, inflammation, and depression in polycystic ovary syndrome: biobehavioral mechanisms and interventions. Fertil Steril. 2010;94(5):1565-74.

19. Dokras A, Clifton S, Futterweit W, Wild R. Increased risk for abnormal depression scores in women with polycystic ovary syndrome: a systematic review and meta-analysis. Obstet Gynecol. 2011;117(1):145-52.

20. Strous RD, Maayan R, Weizman A. The relevance of neurosteroids to clinical psychiatry: from the laboratory to the bedside. Eur Neuropsychopharmacol J Eur Coll Neuropsychopharmacol. 2006;16(3):155-69.

21. Reddy DS. Chapter 8 - Neurosteroids: endogenous role in the human brain and therapeutic potentials. In: Savic I, editor. Progress in brain research [Internet]. Elsevier; 2010 [cited 2021 Feb 17]. p. 113-37. (Sex Differences in the Human Brain, their Underpinnings and Implications; vol. 186). Available from: https://www.sciencedirect.com/science/article/pii/ B9780444536303000087

22. Tuem KB, Atey TM. Neuroactive steroids: receptor interactions and responses. Front Neurol [Internet]. 2017 Aug 28 [cited 2020 Aug 11];8. Available from: https://www.ncbi.nlm.nih.gov/pmc/ articles/PMC5581316/

23. Carver CM, Reddy DS. Neurosteroid interactions with synaptic and extrasynaptic GABA(A) receptors: regulation of subunit plasticity, phasic and tonic inhibition, and neuronal network excitability. Psychopharmacol Berl. 2013;230(2):151-88.

24. McEvoy K, Payne JL, Osborne LM. Neuroactive steroids and perinatal depression: a review of recent literature. Curr Psychiatry Rep. 2018;20(9):78.

25. Dubrovsky B. Neurosteroids, neuroactive steroids, and symptoms of affective disorders. Pharmacol Biochem Behav. 2006;84(4): 644-55.

26. Eser D, Schüle C, Baghai TC, Romeo E, Uzunov DP, Rupprecht R. Neuroactive steroids and affective disorders. Pharmacol Biochem Behav. 2006;84(4):656-66.

27. Haley CL, Sung SC, Rush AJ, Trivedi MH, Wisniewski SR, Luther JF, et al. The clinical relevance of self-reported premenstrual worsening of depressive symptoms in the management of depressed outpatients: a STAR*D report. J Women's Health. 2013;22(3): 219-29.

28. Hsiao M-C, Hsiao C-C, Liu C-Y. Premenstrual symptoms and premenstrual exacerbation in patients with psychiatric disorders. Psychiatry Clin Neurosci. 2004;58(2):186-90.

29. Targum SD, Caputo KP, Ball SK. Menstrual cycle phase and psychiatric admissions. J Affect Disord. 1991;22(1-2):49-53.

30. Crowley SK, O'Buckley TK, Schiller CE, Stuebe A, Morrow AL, Girdler SS. Blunted neuroactive steroid and HPA axis responses to stress are associated with reduced sleep quality and negative affect 
in pregnancy: a pilot study. Psychopharmacol Berl. 2016;233(7): 1299-310.

31. Osborne LM, Betz JF, Yenokyan G, Standeven LR, Payne JL. The role of allopregnanolone in pregnancy in predicting postpartum anxiety symptoms. Front Psychol. 2019;10:1033.

32. Yonkers KA, Vigod S, Ross LE. Diagnosis, pathophysiology, and management of mood disorders in pregnant and postpartum women. Obstet Gynecol. 2011 Apr;117(4):961-77.

33. Trifu S, Vladuti A, Popescu A. The neuroendocrinological aspects of pregnancy and postpartum depression. Acta Endocrinol Buchar 2019;15(3):410-415.

34. Slopien R, Pluchino N, Warenik-Szymankiewicz A, Sajdak S, Luisi $\mathrm{M}$, Drakopoulos $\mathrm{P}$, et al. Correlation between allopregnanolone levels and depressive symptoms during late menopausal transition and early postmenopause. Gynecol Endocrinol. 2018;34(2):144-7.

35. Genazzani AD, Strucchi C, Luisi M, Casarosa E, Lanzoni C, Baraldi E, et al. Metformin administration modulates neurosteroids secretion in non-obese amenorrhoic patients with polycystic ovary syndrome. Gynecol Endocrinol Off J Int Soc Gynecol Endocrinol. 2006;22(1):36-43.

36. Cinar N, Harmanci A, Demir B, Yildiz BO. Effect of an oral contraceptive on emotional distress, anxiety and depression of women with polycystic ovary syndrome: a prospective study. Hum Reprod. 2012;27(6):1840-5.

37. Acmaz G, Albayrak E, Acmaz B, Baser M, Soyak M, Zararsiz G, et al. Level of anxiety, depression, self-esteem, social anxiety, and quality of life among the women with polycystic ovary syndrome. ScientificWorldJournal. 2013/08/13 ed. 2013;2013:851815.

38. Adali E, Yildizhan R, Kurdoglu M, Kolusari A, Edirne T, Sahin $\mathrm{HG}$, et al. The relationship between clinico-biochemical characteristics and psychiatric distress in young women with polycystic ovary syndrome. J Int Med Res. 2008;36(6):1188-96.

39. Amiri M, Bidhendi Yarandi R, Nahidi F, Tohidi M, Ramezani TF. The relationship between clinical and biochemical characteristics and quality of life in patients with polycystic ovary syndrome. Clin Endocrinol Oxf. 2019;90(1):129-37.

40. Annagür BB, Tazegül A, Uguz F, Kerimoglu ÖS, Tekinarslan E, Celik Ç. Biological correlates of major depression and generalized anxiety disorder in women with polycystic ovary syndrome. J Psychosom Res. 2013;74(3):244-7.

41. Annagur BB, Tazegul A, Akbaba N, et al. Noro Psikiyatr Ars. 2014/06/01 ed. 2014;51(2):129-32.

42. Arshad M, Moradi S, Ahmmadkhani A, Emami Z. Increased prevalence of depression in women with polycystic ovary syndrome. Iran J Endocrinol Metab. January 1. 13.

43. Asik M, Altinbas K, Eroglu M, Karaahmet E, Erbag G, Ertekin H, et al. Evaluation of affective temperament and anxiety-depression levels of patients with polycystic ovary syndrome. J Affect Disord. 2015;185:214-8.

44. Barnard L, Ferriday D, Guenther N, Strauss B, Balen AH, Dye L. Quality of life and psychological well being in polycystic ovary syndrome. Hum Reprod. 2007/06/01 ed. 2007;22(8):2279-86.

45. Barry JA, Hardiman PJ, Saxby BK, Kuczmierczyk A. Testosterone and mood dysfunction in women with polycystic ovarian syndrome compared to subfertile controls. J Psychosom Obstet Gynaecol. 2011;32(2):104-11.

46. Benson S, Janssen OE, Hahn S, Tan S, Dietz T, Mann K, et al. Obesity, depression, and chronic low-grade inflammation in women with polycystic ovary syndrome. Brain Behav Immun. 2008;22(2):177-84.

47. Benson S, Hahn S, Tan S, Mann K, Janssen OE, Schedlowski M, et al. Prevalence and implications of anxiety in polycystic ovary syndrome: results of an internet-based survey in Germany. Hum Reprod Oxf Engl. 2009;24(6):1446-51.
48. Bhattacharya SM, Jha A. Prevalence and risk of depressive disorders in women with polycystic ovary syndrome (PCOS). Fertil Steril. 2010;94(1):357-9.

49. Cesta CE, Kuja-Halkola R, Lehto K, Iliadou AN, Landen M. Polycystic ovary syndrome, personality, and depression: a twin study. Psychoneuroendocrinology. 2017/08/22 ed. 2017;85:63-8.

50. Cinar N, Kizilarslanoglu MC, Harmanci A, Aksoy DY, Bozdag G, Demir B, et al. Depression, anxiety and cardiometabolic risk in polycystic ovary syndrome. Hum Reprod Oxf Engl. 2011;26(12): 3339-45.

51. Davari Tanha F, Mohseni M, Ghajarzadeh M. Sexual function in women with primary and secondary infertility in comparison with controls. Int J Impot Res. 2014/01/17 ed. 2014;26(4):132-4.

52. Deeks. Is having polycystic ovary syndrome a predictor of poor psychological function including anxiety and depression? Hum Reprod. 2011;(26):1399-407.

53. Elsenbruch S, Hahn S, Kowalsky D, Offner AH, Schedlowski M, Mann K, et al. Quality of life, psychosocial well-being, and sexual satisfaction in women with polycystic ovary syndrome. J Clin Endocrinol Metab. 2003;88(12):5801-7.

54. Ercan CM, Coksuer H, Aydogan U, Alanbay I, Keskin U, Karasahin KE, et al. Sexual dysfunction assessment and hormonal correlations in patients with polycystic ovary syndrome. Int J Impot Res. 2013;25(4):127-32.

55. Hahn S, Janssen OE, Tan S, Pleger K, Mann K, Schedlowski M, et al. Clinical and psychological correlates of quality-of-life in polycystic ovary syndrome. Eur J Endocrinol. 2005/12/03 ed. 2005; 153(6):853-60.

56. Harmanci A, Cinar N, Bayraktar M, Yildiz BO. Oral contraceptive plus antiandrogen therapy and cardiometabolic risk in polycystic ovary syndrome. Clin Endocrinol. 2013;78(1):120-5.

57. Hart R, Doherty DA. The potential implications of a PCOS diagnosis on a woman's long-term health using data linkage. J Clin Endocrinol Metab. 2014/12/23 ed. 2015;100(3):911-9.

58. Himelein MJ, Thatcher SS. Depression and body image among women with polycystic ovary syndrome. J Health Psychol. 2006/06/14 ed. 2006;11(4):613-25.

59. Hung JH, Hu LY, Tsai SJ, Yang AC, Huang MW, Chen PM, et al. Risk of psychiatric disorders following polycystic ovary syndrome: a nationwide population-based cohort study. PLoS One. 2014;9(5): e97041.

60. Hussain A, Chandel RK, Ganie MA, Dar MA, Rather YH, Wani $\mathrm{ZA}$, et al. Prevalence of psychiatric disorders in patients with a diagnosis of polycystic ovary syndrome in Kashmir. Indian $\mathrm{J}$ Psychol Med. 2015/02/28 ed. 2015;37(1):66-70.

61. Jedel E, Gustafson D, Waern M, Sverrisdottir YB, Landen M, Janson PO, et al. Sex steroids, insulin sensitivity and sympathetic nerve activity in relation to affective symptoms in women with polycystic ovary syndrome. Psychoneuroendocrinology. 2011;36(10):1470-9.

62. Jedel E, Waern M, Gustafson D, Landén M, Eriksson E, Holm G, et al. Anxiety and depression symptoms in women with polycystic ovary syndrome compared with controls matched for body mass index. Hum Reprod Oxf Engl. 2010;25(2):450-6.

63. Klimczak D, Szlendak-Sauer K, Radowicki S. Depression in relation to biochemical parameters and age in women with polycystic ovary syndrome. Eur J Obstet Gynecol Reprod Biol. 2015 Jan;184: 43-7.

64. Laggari V, Diareme S, Christogiorgos S, Deligeoroglou E, Christopoulos P, Tsiantis J, et al. Anxiety and depression in adolescents with polycystic ovary syndrome and Mayer-RokitanskyKuster-Hauser syndrome. J Psychosom Obstet Gynaecol. 2009/06/ 18 ed. 2009;30(2):83-8.

65. Moran LJ, March WA, Whitrow MJ, Giles LC, Davies MJ, Moore VM. Sleep disturbances in a community-based sample of women 
with polycystic ovary syndrome. Hum Reprod Oxf Engl. 2015;30(2):466-72.

66. Moran LJ, Deeks AA, Gibson-Helm ME, Teede HJ. Psychological parameters in the reproductive phenotypes of polycystic ovary syndrome. Hum Reprod Oxf Engl. 2012;27(7):2082-8.

67. Moran L, Gibson-Helm M, Teede H, Deeks A. Polycystic ovary syndrome: a biopsychosocial understanding in young women to improve knowledge and treatment options. J Psychosom Obstet Gynaecol. 2010;31(1):24-31.

68. Naqvi SH, Moore A, Bevilacqua K, Lathief S, Williams J, Naqvi N, et al. Predictors of depression in women with polycystic ovary syndrome. Arch Womens Ment Health. 2015;18(1):95-101.

69. Özenli Y, Haydardedeoğlu B, Micozkadioğlu I, Şimșek E, Kiliçdağ E, Bagis T. Anxiety, depression and ways of coping skills by women with polycystic ovary syndrome: a controlled study. J Turk Ger Gynecol Assoc. January 1. 9:190-4.

70. Rahiminejad ME, Moaddab A, Rabiee S, Esna-Ashari F, Borzouei S, Hosseini SM. The relationship between clinicobiochemical markers and depression in women with polycystic ovary syndrome. Iran J Reprod Med. 2014;12(12):811-6.

71. Rassi A, Veras AB, dos Reis M, Pastore DL, Bruno LM, Bruno $\mathrm{RV}$, et al. Prevalence of psychiatric disorders in patients with polycystic ovary syndrome. Compr Psychiatry. 2010;51(6):599-602.

72. Rocco A, Falaschi P, Perrone G, Pancheri P, Rosa M, Zichella L. Psychoneuroendocrine aspects of polycystic ovary syndrome. J Psychosom Obstet Gynecol. 1991;12(2):169-79.

73. Sayyah-Melli M, Alizadeh M, Pourafkary N, Ouladsahebmadarek E, Jafari-Shobeiri M, Abbassi J, et al. Psychosocial factors associated with polycystic ovary syndrome: a case control study. J Caring Sci. 2015/10/16 ed. 2015;4(3):225-31.

74. Shi X, Zhang L, Fu S, Li N. Co-involvement of psychological and neurological abnormalities in infertility with polycystic ovarian syndrome. Arch Gynecol Obstet. 2011;284(3):773-8.

75. Soyupek F, Guney M, Eris S, Cerci S, Yildiz S, Mungan T. Evaluation of hand functions in women with polycystic ovary syndrome. Gynecol Endocrinol. 2008/11/18 ed. 2008;24(10):571-5.

76. Weiner CL, Primeau M, Ehrmann DA. Androgens and mood dysfunction in women: comparison of women with polycystic ovarian syndrome to healthy controls. Psychosom Med. 2004;66(3):356-62.

77. Goodarzi MO, Carmina E, Azziz R. DHEA, DHEAS and PCOS. J Steroid Biochem Mol Biol. 2015;145:213-25.

78. Hedstrom H, Backstrom T, Bixo M, Nyberg S, Wang M, Gideonsson I, et al. Women with polycystic ovary syndrome have elevated serum concentrations of and altered GABA(A) receptor sensitivity to allopregnanolone. Clin Endocrinol Oxf. 2015;83(5):643-50.

79. Saito K, Matsuzaki T, Iwasa T, Miyado M, Saito H, Hasegawa T, et al. Steroidogenic pathways involved in androgen biosynthesis in eumenorrheic women and patients with polycystic ovary syndrome. J Steroid Biochem Mol Biol. 2016;158:31-7.

80. Keefe CC, Goldman MM, Zhang K, Clarke N, Reitz RE, Welt CK. Simultaneous measurement of thirteen steroid hormones in women with polycystic ovary syndrome and control women using liquid chromatography-tandem mass spectrometry. PLoS One. 2014;9(4): e93805.

81. Saito K, Matsuzaki T, Iwasa T, Miyado M, Saito H, Kubota T, et al. Blood allopregnanolone levels in women with polycystic ovary syndrome. Clin Endocrinol. 2016;85(1):151-2.

82. Jedel E, Waern M, Gustafson D, Landen M, Eriksson E, Holm G, et al. Anxiety and depression symptoms in women with polycystic ovary syndrome compared with controls matched for body mass index. Hum Reprod. 2010;25(2):450-6.

83. Maguire J, Mody I. GABA(A)R plasticity during pregnancy: relevance to postpartum depression. Neuron. 2008;59(2):207-13.
84. Giltay EJ, Enter D, Zitman FG, Penninx BW, van Pelt J, Spinhoven $\mathrm{P}$, et al. Salivary testosterone: associations with depression, anxiety disorders, and antidepressant use in a large cohort study. J Psychosom Res. 2012;72(3):205-13.

85. Genazzani AD, Ricchieri F, Lanzoni C. Use of metformin in the treatment of polycystic ovary syndrome. Womens Health. 2010;6(4):577-93.

86. Backstrom T, Bixo M, Johansson M, Nyberg S, Ossewaarde L, Ragagnin $\mathrm{G}$, et al. Allopregnanolone and mood disorders. Prog Neurobiol. 2014;113:88-94.

87. McEvoy K, Osborne LM. Allopregnanolone and reproductive psychiatry: an overview. Int Rev Psychiatry Abingdon Engl. 2019;31(3):237-44.

88. Genazzani AD, Ricchieri F, Lanzoni C. Use of metformin in the treatment of polycystic ovary syndrome: women's health [Internet]. 2010 Jul 1 [cited 2019 Dec 18]; Available from: https://doi.org/10. 2217/WHE.10.43?icid=int.sj-full-text.similar-articles.2.

89. Giuliani FA, Yunes R, Mohn CE, Laconi M, Rettori V, Cabrera R. Allopregnanolone induces LHRH and glutamate release through NMDA receptor modulation. Endocrine. 2011;40(1):21-6.

90. Laconi MR, Chavez C, Cavicchia JC, Fóscolo M, Sosa Z, Yunes $\mathrm{RF}$, et al. Allopregnanolone alters the luteinizing hormone, prolactin, and progesterone serum levels interfering with the regression and apoptosis in rat corpus luteum. Horm Metab Res Horm Stoffwechselforschung Horm Metab. 2012;44(8):632-8.

91. Pelegrina LT, Cáceres ARR, Giuliani FA, Asensio JA, Parborell F, Laconi MR. A single dose of allopregnanolone affects rat ovarian morphology and steroidogenesis. Reproduction. 2017;153(1):75-83.

92. Genazzani AD, Chierchia E, Rattighieri E, Santagni S, Casarosa E, Luisi M, et al. Metformin administration restores allopregnanolone response to adrenocorticotropic hormone (ACTH) stimulation in overweight hyperinsulinemic patients with PCOS. Gynecol Endocrinol Off J Int Soc Gynecol Endocrinol. 2010;26(9):684-9.

93. Hahn S, Benson S, Elsenbruch S, Pleger K, Tan S, Mann K, et al. Metformin treatment of polycystic ovary syndrome improves health-related quality-of-life, emotional distress and sexuality. Hum Reprod. 2006;21(7):1925-34.

94. Steiner M, Pearlstein T, Cohen LS, Endicott J, Kornstein SG, Roberts C, et al. Expert guidelines for the treatment of severe PMS, PMDD, and comorbidities: the role of SSRIs. J Womens Health 2002. 2006;15(1):57-69.

95. Giuliani FA, Escudero C, Casas S, Bazzocchini V, Yunes R, Laconi $\mathrm{MR}$, et al. Allopregnanolone and puberty: modulatory effect on glutamate and GABA release and expression of 3 alphahydroxysteroid oxidoreductase in the hypothalamus of female rats. Neuroscience. 2013;243:64-75.

96. Blank SK, McCartney CR, Marshall JC. The origins and sequelae of abnormal neuroendocrine function in polycystic ovary syndrome. Hum Reprod Update. 2006;12(4):351-61.

97. Genazzani AD, Luisi M, Malavasi B, Strucchi C, Luisi S, Casarosa E, et al. Pulsatile secretory characteristics of allopregnanolone, a neuroactive steroid, during the menstrual cycle and in amenorrheic subjects. Eur J Endocrinol. 2002;146(3):347-56.

98. Genazzani AR, Petraglia F, Bernardi F, Casarosa E, Salvestroni C, Tonetti A, et al. Circulating levels of allopregnanolone in humans: gender, age, and endocrine influences. J Clin Endocrinol Metab. 1998;83(6):2099-103.

Publisher's Note Springer Nature remains neutral with regard to jurisdictional claims in published maps and institutional affiliations. 